\title{
Inteligência artificial aplicada à criação artística: a emergência do novo artífice
}

Erik Nardini Medina ${ }^{1}$ Mauricius Martins Farina ${ }^{2}$

\section{Introdução}

A IMINÊNCIA DOS DESENVOLVIMENTOS TECNOCIENTÍFICOS TEM AMPLIADO AS MANEIRAS COMO ARTISTAS PODEM SE expressar, sobretudo mediante a adoção e colaboração com interfaces inteligentes, que de modo cada vez mais acelerado assimilam qualidades humanas e são capazes de assistir a criação. Deste cenário emergem possibilidades colaborativas que se fortalecem sob o acoplamento homem-máquina, perspectiva que resulta em um cenário que embaralha a práxis, se materializa na hibridação e reconhece o corpo enquanto metáfora para simbolizar sistemas complexos, ambos orgânicos e inorgânicos ${ }^{3}$.

Acentua-se neste sentido o reconhecimento do homem e da máquina enquanto seres com valores equivalentes sob uma perspectiva que visa "romper com a visão hegemônica de controle de uma instância sobre a outra [homem versus máquina], e compreender as múltiplas possibilidades de relacionamentos horizontais, transversais, e não exclusivamente verticais, entre corpos de naturezas distintas" ${ }^{\prime 4}$. Este entendimento parece determinante para o pensamento da arte realizada por intermédio de interfaces inteligentes que podem ser experimentadas atualmente.

O cenário que se estabelece no século XXI amplifica as potencialidades do ecossistema criativo numerizado, uma vez que os desenvolvimentos no campo da informática têm aceleradamente permitido o desenvolvimento e a incorporação de dispositivos de input e output capazes de permitir às interfaces a compreensão de subjetividades puramente biológicas como emoção, afeto e sociabilidade ${ }^{5}$. Esses conceitos, quando aplicados às interfaces inteligentes, acentuam a antropomorfização das máquinas em uma dinâmica que emerge do progresso tecnológico e se estabelece na fronteira da computação cognitiva, um cenário em que máquinas podem interpretar não apenas linguagens, mas sensações. Este é um componente valioso quando se atua na esfera das artes de maneira geral.

\footnotetext{
${ }^{1}$ Doutorando em Artes Visuais - História, Teoria e Crítica pelo Programa de Pós-graduação em Artes Visuais do Instituto de Artes/Universidade Estadual de Campinas (IA/Unicamp). Contato: eriknardini@live.com.

2 Professor Livre-Docente do Instituto de Artes da Universidade Estadual de Campinas (IA/Unicamp). ORCID: https://orcid.org/0000-0003-4751-5266. Contato: mmfarina@unicamp.br.

${ }^{3}$ ZuANON, R. Computador Vestível Afetivo Co-evolutivo: processos de comunicação entre corpos biológico e tecnológico. Tese. Programa de Doutorado em Comunicação e Semiótica, Pontifícia Universidade Católica de São Paulo, 2007.

${ }^{4}$ Idem. Biointerfaces inteligentes: transdisciplinaridade e transversalidade em arte-arquitetura-design-ciência-tecnologia. In: Celeste, H. et al. (ORG.). Transdisciplinaridade nas Ciências e nas Artes. Santa Maria: Editora PPGART, 2020, p. 238.

${ }^{5}$ SUCHMAN, L. Human-machine reconfigurations: plans and situated actions. Cambridge: Cambridge Univ. Press, 2007.
} 
O paradigma de interfaces cada vez mais empáticas, algo permitido sobretudo em razão da solidificação de uma nova onda ${ }^{6}$ de Inteligência Artificial (IA), que é capaz de aprender com imagens em uma dinâmica muito mais natural e lúdica do que aquela vista em operações baseadas em GOFAI (Good Old-Fashioned Artificial Intelligence) ${ }^{7}$, pavimenta um caminho que incentiva e facilita a criação com sistemas artificiais complexos. Essa nova onda de IA, que opera a partir de algoritmos poderosos suportados por redes neurais, que pode se associar a dispositivos de comunicação que analisam comportamentos e estados corpóreos e os convertem em dados numéricos, são elementos que simbolizam o prelúdio de uma arte estritamente contemporânea, o nascimento de imagem nova.

Mas, apesar do sabor de novidade, a questão do ecossistema criativo que se agarra ao numérico no exercício poético não é exatamente nova. Sua origem está nos anos 1960 e se estabelece praticamente ao mesmo tempo que a vanguarda da arte conceitual, movimento que se espalhou pela Europa e pelos Estados Unidos e cujo principal atributo está em enfatizar a ideia em detrimento do artefato, removendo a necessidade de que a obra seja construída pelas mesmas mãos daquele(a) que conceituou o objeto $^{8}$. O marco da arte numerizada, contudo, fora estabelecido pela exposição Cybernetic Serendipity (1968), que teve como objetivo apresentar formas pelas quais os seres humanos poderiam usar computadores e novas tecnologias para ampliar sua criatividade. Ao mesmo tempo, o início da jornada de Harold Cohen/AARON (1968), tendo outros nomes como Vera Molnár, Frieder Nake e A. Michael Noll como entusiastas pioneiros, contribuiu para que o interesse pelas artes gestadas parcialmente por sistemas numerizados ganhasse dimensão e envergadura e pavimentou o caminho à contemporaneidade que hoje dispõe de entidades altamente complexas - interfaces inteligentes de auxílio à criação artística. Dentre elas está a plataforma Playform, que surge como objeto candidato a representar as questões deste artigo e que será explorada adiante.

Embora teóricos e artistas já explorem as potencialidades homem-máquina há tempos, este é um tema que está longe de ter suas questões esgotadas. O cenário que se estabelece a partir da confluência e da profusão de elementos nativos da informática e da própria ciência cognitiva ${ }^{9}$, e que ganha tração sobretudo no século XXI, permite recolocar em perspectiva a adoção de sistemas inorgânicos enquanto agentes criativos. Da simbiose entre os corpos surgem dilemas que exigem atualização permanente: autoria maquínica, criatividade inorgânica, modos de produção contemporânea (tensionando o papel do artista e do sistema na práxis).

Qual seria o caminho metodológico mais adequado para tratar essas questões? A autoria já não foi exaustivamente debatida? Não seria a criatividade uma condição inata aos seres humanos? Sistemas inteligentes não são meros instrumentais? Se partíssemos do pressuposto que sistemas baseados em IA são ferramentas ou linguagens, talvez pudéssemos responder a esses problemas e encerrar as questões, mas as soluções apresentadas por quaisquer das hipóteses acima sugeridas careceriam de substância e seriam potencialmente superficiais. A metodologia, baseada em uma concisa revisão bibliográfica que explora a reflexão

\footnotetext{
${ }^{6}$ Elgammal, A.; Mazzone, M. Artists, Artificial Intelligence and Machine-based Creativity in Playform. Artnodes, [S. 1.], n. 26, 2020. Disponível em: <https://doi.org/10.7238/a.v0i26.3366>. Acesso em: 08/09/2021; e POLTRONIERI, F.; HÄNSKA, M. Technical Images and Visual Art in the Era of Artificial Intelligence: From GOFAI to GANs. Disponível em: <https://doi.org/10.1145/3359852.3359865>. 2019. Acesso em: 08/09/2021.

${ }^{7}$ Haugeland, J. Artificial Intelligence: The Very Idea. Massachussets: MIT Press, 1985.

${ }^{8}$ Essa atitude poética, ainda que pertencente a uma vanguarda distinta, revela um sintoma percebido também na arte desenvolvida sob dinâmicas híbridas: o movimento de cessão criativa, a ser visto adiante, parece estar de alguma forma associado à ideia da "inexigência do fazer pelo artista”. Há, contudo, obras que são imaginadas por um artista e produzidas por interfaces inteligentes, e outras que são imaginadas pelo artista $e$ por interfaces inteligentes, o que acaba por complexificar a comparação ao incluir uma imaginação descorporificada. A associação, contudo, é oportuna. Cf.: Wood, P. Arte conceitual. São Paulo: Cosac \& Naify, 2004.

${ }^{9}$ Haugeland, Op. cit., p. 5.
} 
sobre imagens técnicas e a ciência cognitiva, sobretudo no âmbito da Inteligência Artificial, oferece o pano de fundo para o desenvolvimento deste artigo.

A dimensão que a IA assumiu e a celeridade com que novas habilidades são constantemente incorporadas - desenvolvidas não raramente a partir de pensamentos não-humanos e de modo não supervisionado - permitem assegurarmos que: 1) estes sistemas não são meras ferramentas e; 2) a IA não deve ser considerada apenas linguagem. A expressão "corpos inorgânicos" parece reunir os elementos adequados para articular e ratificar a existência de um novo e misterioso paradigma de artífice, um artífice que estabelece seus próprios meios e não raramente surpreende pelo ineditismo de suas imaginações.

Contudo, nem sempre o papel de interfaces numerizadas foi tão amplamente reconhecido. Os primórdios da criatividade assistida por sistemas inteligentes e computadorizados exigiu de seus pioneiros profundo conhecimento em linguagens de programação para que criações pudessem emergir de tais colaborações híbridas - e não raramente, era requerido do artista a associação com engenheiros e especialistas capazes de transformar o desejo artístico em linguagem de máquina ${ }^{10}$. A compreensão desses fatores pressupõe a necessidade do reconhecimento de suas origens visando à percepção das diferenças e à assimilação das possibilidades atuais, imprevistas até poucas décadas atrás.

\section{Regras programadas}

Harold Cohen foi o visionário que, ainda na aurora da IA (termo cunhado em 1956 por John McCarthy, durante conferência no Dartmouth College), popularizou o uso de algoritmos para o desenvolvimento de imagens técnicas e obras de arte com o claro objetivo de desenvolver um método capaz de criar pinturas de modo autônomo. Seu desafio surgira de um impulso criativo que não mais podia se satisfazer em escala biológica, condição que o levou a programar AARON, software que emularia a cognição e deveria apresentar características que fossem semelhantes ao sistema cognitivo humano.

Apesar das pretensões sugerirem um sistema autônomo, as obras de arte criadas por AARON tinham como base as regras que Cohen programava - era, portanto, um código intensamente dependente do agente humano -, e o sistema passou por inúmeras atualizações ao longo dos quarenta anos de colaborações com Cohen. Muito embora as diretrizes fossem codificadas pelo artista e deste dependessem para exibir suas criações, o programa era capaz de gerar uma variedade de desenhos virtualmente infinita e com resultados diferentes em cada nova rodada, resultando em figuras quase sempre imprevistas por seu criador. Seria este um sintoma de criatividade artificial? Para Cohen, a criatividade era um ponto relativo:

Claramente a máquina está sendo criativa, o programa está sendo criativo na medida em que cada vez que faz um desenho, faz um desenho que ninguém jamais viu antes, inclusive eu. Eu não acho que a máquina, atualmente, seja tão criativa quanto eu sou ao escrever o programa. Eu acho que, para um programa ser totalmente criativo, num sentido mais completo de criatividade, ele tem que ser capaz de modificar seu próprio desempenho. E este é um problema muito difícil ${ }^{11}$

Cohen estava certo ao classificar como "muito difícil" a solução para um programa que tivesse habilidades de modificar a si mesmo. Afinal, antever, no epílogo dos anos 80 , a forma como evoluiriam os algoritmos nas décadas subsequentes era uma

\footnotetext{
${ }^{10}$ ReICHARDT, J. Computer Art. In: Reichardt, J. (ORG.). Cybernetic Serendipity: The computer and the Arts. Londres: Studio International, 1968, p. 71.

${ }^{11}$ Trecho de entrevista de Harold Cohen concedida a Ray Kurzweil que integra o documentário The Age of Intelligent Machines (1987), tradução nossa.
} 
tarefa nebulosa. É verdade, o problema de algoritmos generativos e não supervisionados continua sendo complexo, mas não se trata mais de uma questão mal resolvida ou impraticável: interfaces artificiais complexas subsidiadas por redes neurais (especialmente Redes Adversárias Generativas ou GANs), baseadas em sistemas alicerçados em computação afetiva (campo dedicado à formulação de máquinas que exibam habilidades afetivas, tais como reconhecer, expressar, modelar e responder à emoção $)^{12}$, sociabilidade e os diferentes vetores - machine learning, deep learning, computer vision - oriundos da Inteligência Artificial revelam-se cada vez mais disponíveis e numerosos.

E, de fato, isso tem acontecido com elevada velocidade, sobretudo se o recorte temporal se deslocar para o segundo decênio do século XXI, período que tem sido o berço de uma porção de evoluções tecnológicas cujos saltos em automação e inteligência artificial se revelam surpreendentes, culminando em um ponto em que, atualmente, é de certa maneira inevitável fazer referência às máquinas ou às interfaces inteligentes sem adotar uma atitude antropomórfica, com tendências à humanização. Pudera, interfaces inteligentes são dimensões virtualizadas do sensível, organismos inorgânicos avançados com a peculiar qualidade de serem capazes de, diante de conjuntos de dados, operar e criar. Se não da mesma forma que o fazem os humanos, ao menos de maneiras curiosamente criativas.

\section{o novo artífice de imagens técnicas}

Semelhantes (em conceito) ao parceiro sintético de Harold Cohen, as entidades inteligentes aqui investigadas são representadas por sistemas complexos e virtualizados, dotados de inteligência inorgânica capazes de assistir ou colaborar com o desenvolvimento e produção de obras artísticas que se apresentam (principalmente, mas não exclusivamente) sob a forma de imagens técnicas, isto é, imagens produzidas por meio de aparelhos e que, por sua vez, são produtos do texto científico aplicado.

Imagens elaboradas com o auxílio de entidades inteligentes (nível do software, não do hardware) carecem de indexicalidade porque têm como origem apenas pontos e cálculos, diferenciando-se, portanto, de imagens técnicas obtidas a partir de aparatos (pensemos em câmeras), que se agarram a objetos ou fenômenos, efêmeros ou não, que existem ou acontecem no âmbito tridimensional e que são passíveis de serem experienciados pelo corpo em uma ou mais escalas sensoriais. Imagens algorítmicas, por sua vez, sempre apontam para fórmulas matemáticas e conceitos abstratos e são, em partes, consequências de imaginações numéricas.

Imagens técnicas são produtos de lógica programada ${ }^{13}$, e é justamente essa lógica que compõe o background das interfaces inteligentes aqui investigadas, já que estas funcionam mediante a compilação de algoritmos - códigos que processam dados, os convertem em informações e permitem a inteligência artificial -, emaranhados lógico-matemáticos que, amiúde, revelamse compreensíveis apenas a especialistas e programadores. No entanto, a migração desta linguagem codificada e hermética em direção a interfaces gráficas, mais amigáveis aos usuários comuns, parece estar se tornando realidade e expondo a faceta de um artífice numerizado.

Em um movimento que remete à revolução promovida com o lançamento da versão 1 do Windows, primeira tentativa da Microsoft de reformular a experiência de uso dos sistemas operacionais em 1985 (viabilizando a migração de sistemas baseados em DOS para sistemas gráficos), interfaces como a Playform têm, aos poucos, retirado a exigência do profundo conhecimento algorítmico enquanto pré-requisito para permitir a comunicação homem-máquina, tendo como objetivo facilitar a cooperação de ambos os atores na esfera do criativo.

\footnotetext{
12 PICARD, R. Affective computing: challenges. International Journal of Human-Computer Studies. Londres, v. 59, p. 5564, 2003. Disponível em: <https://doi.org/10.1016/S1071-5819(03)00052-1>. Acesso em: 08/09/2021.

${ }^{13}$ FLUSSER, V. O universo das imagens técnicas: elogio da superficialidade. São Paulo: Annablume, 2008.
} 
A Playform é uma interface inteligente baseada em IA, um sistema inorgânico e criativo cuja face visível do cérebro virtualizado pode ser acessada por meio de um hiperlink ${ }^{14}$. Ao mesmo tempo, a plataforma é considerada uma ativa colaboradora para a legião de artistas que a ela se associam para dar forma a impulsos criativos latentes ou inesperados.

O sistema que dá vida à Playform é baseado em uma classe de redes neurais chamada de Redes Adversárias Generativas (Generative Adversarial Network ou GANs no acrônimo em inglês). Para colaborar com o sistema, o artista é convidado a fazer upload de imagens que serão utilizadas para treinar as redes neurais dedicadas a assistir a um determinado projeto (originar obras). Quanto maior o tempo de treinamento (da Playform) e maior a quantidade de imagens submetidas ao sistema, maior a qualidade dos outputs, que tendem a ser mais acurados e semelhantes aos dados oferecidos ao treinamento da rede neural. A tarefa de aprendizagem pode levar minutos, horas ou dias ${ }^{15}$.

O treinamento, a propósito, é uma das etapas mais críticas do novo paradigma IA: exceto em casos excepcionais como é o caso da Playform, é preciso certa dose de conhecimento para colocar redes neurais em funcionamento (desde compilar, descarregar e configurar bibliotecas de imagens e de códigos, testar, debugar ou corrigir erros inesperados), sem mencionar a exigência por capacidade de processamento informático (redes neurais são conhecidas pelo apetite voraz por processamento $)^{16}$. A quantidade de elementos que precisam ser combinados para dar vida à inteligência artificial e fazer correr impulsos inorgânicos através de neurônios digitais exige tempo, conhecimento e recursos.

A etapa de treinamento precede (é condição para) o aprendizado de máquina, motor que permite às interfaces inteligentes a apreensão de conceitos tão intangíveis quanto a estética artística, e isso se estabelece a partir de treinamentos em conjuntos de imagens aos quais os algoritmos são submetidos. Ao serem alimentados com os dados que compõem o dataset que o artista deseja emular, os algoritmos são capazes de absorver padrões, encontrar semelhanças e gerar resultados inéditos a partir deste aprendizado. Resultados intermediários (obtidos durante o período de treinamento) são frequentemente ruidosos, apresentam severas deformações e se aproximam da estética glitch, algo que costuma ser desejável para alguns artistas.

A cooperação homem-máquina apresentada acima se estabelece em duas dimensões distintas: enquanto o sujeito humano tem suas raízes fincadas na esfera tridimensional, as interfaces inteligentes atuam no âmbito zerodimensional ${ }^{17}$. A dinâmica que se organiza a partir da colaboração que une corpos de diferentes naturezas em esferas conectadas por relações estritamente simbólicas representa um rompimento com as formas de produção artística tradicionais. Esse rompimento se acentua na inexigência de espaços físicos (seja para apreciação das obras, seja para a produção destas) uma vez que imagens estáticas ou não, vídeos e literatura (em suma, conteúdos) gestados digitalmente ocupam um espaço que se arquiteta sob a forma de rede. Essa rede virtualizada articula início (processo de criação que pressupõe a simbiose homem-máquina), meio (de exibição ou de consumo) e fim das obras (obsolescência da obra ou reformulação de si mesma). Trata-se de um ciclo completo, independente e artificial.

A exigência da fisicalidade ou de performances efêmeras, seja para originar as obras, seja para exibi-las, portanto, tornase tangencial à medida que os únicos estímulos necessários à alimentação de sistemas inorgânicos, a priori, são aqueles simbólicos: os algoritmos que operam as interfaces “(...) remixam as formas disponíveis e fazem uso de dados”" Dados remixados compõem a pedra fundamental sob a qual a geração de conteúdos visuais inéditos e imprevistos emergem. Estes conjuntos de dados são tratados (remixados) a partir de imaginações numerizadas que agrupam, assimilam e reformulam

\footnotetext{
${ }^{14}$ PLAYForm. Disponível em: <https://www.playform.io/>. Acesso em: 15/05/2021.

${ }^{15}$ PlaYForm - FAQ. Disponível em: <https://playform.gitbook.io/playform/>. Acesso em: 03/06/2021.

${ }^{16}$ POLTRONIERI; HÄNSKA, op. cit., p. 6.

${ }^{17}$ FLUSSER, op. cit., p. 23.
}

${ }^{18}$ Bourriaud, N. Postproduction: Culture as Screenplay: How Art Reprograms the World, New York: Lukas \& Sternberg, 2002, p. 16, tradução nossa. 
padrões apreendidos e extraídos destes mesmos conjuntos (que podem ser imagens, mas também podem ser qualquer coisa) e permitem o surgimento de obras.

A poética destas obras depende majoritariamente do background ao qual uma determinada interface inteligente é submetida (quais foram os substratos/conjuntos de dados/imagens oferecidos ao algoritmo para sua aprendizagem), mas também está sujeita à própria intervenção do agente humano atuando em colaboração com a interface, já que é sempre possível que este interagente, na condição de coautor, faça modificações durante os estágios de pós-produção. Apesar de ser o responsável pelo conteúdo sobre o qual o sistema inteligente será treinado, o agente humano é privado de qual será o resultado da imaginação do artífice algorítmico. Essa é uma das principais características que permite considerar o corpo inorgânico enquanto parte determinante da cadeia criativa. Esse estar em suspensão da imagem imprime um ritmo diferente à criação e impõe à obra um misterioso estado de potência.

Seria o novo artífice, nesse sentido, o equivalente contemporâneo da caixa preta ${ }^{19}$ flusseriana? Embora tal compreensão não seja necessariamente desejável, na medida em que o ideal é a busca pela extrapolação da caixa e o afastamento de mitos e magias, a analogia parece ser aplicável de modo satisfatório ao permitir constatar que o novo artífice é uma entidade que transcodifica texto em imagens, mas também imagens em imagens, números em imagens, sinais em imagens. Tudo pode ser convertido em imagens porque a caixa preta aceita, amiúde, todo o tipo de input.

Mas, afinal, quais são essas imagens? São imagens latentes, e esse é um aspecto fundamental para se pensar em entidades enquanto interagentes cocriadores. Diante das possibilidades vislumbradas no que chamamos novo artífice, parece haver um sintoma heurístico que permite a essas interfaces produzirem algo inovador e não apenas pseudo simulacros ${ }^{20}$. Algo genuinamente novo surge de um sistema, emerge da singularidade inerente à arte generativa ${ }^{21}$. O fator da obra em potência, que acentua a coautoria e que pode ser entendido como um dos principais elementos no rompimento da hegemonia que coloca o homem sobre a máquina, parece instituir uma dinâmica de criação que, aparentemente, só pode se concretizar no reconhecimento de corpos de diferentes naturezas.

Essa nova dinâmica ilumina o entendimento da desmaterialização da arte, condição que se estabelece, conforme sugere Flusser, na própria zerodimensionalidade ${ }^{22}$. Tal dimensão supra material produz tecnoimagens, textos científicos por essência, manifestações visuais isentas de dimensionalidade e de índice por terem como referencial exclusivamente os elementos próprios de um espectro fenomênico. A potência dessa nova ecologia do sensível está no fato de que as plataformas ou sistemas inorgânicos complexos são capazes de dar "forma a um mundo baseado apenas em dados" 23 , condição que aponta a algo impalpável e que só pode ser experimentado em esferas virtualizadas ou digitalizadas.

Isso ocorre em virtude do que ousaremos tratar como imaginação maquínica, imaginação que é fruto de uma cognição desencarnada - condição esta que parece romper com a dependência de inputs da dimensão natural, muito embora o novo artífice possa aprender com elementos do mundo exterior. Essa relação cria uma espécie de dobradura em que a arte está no centro, um movimento que se delineia em uma geografia do "entre”: entre o mundo natural e o simbólico e virtual. A arte artificializada, portanto, se estabelece entre os domínios da realidade virtual e descorporificada e da dimensão biológica e material.

A confluência (que pressupõe o compartilhamento do poder criativo do artista-operador com as interfaces) desencadeia uma dinâmica de coautoria que difere daquela dinâmica autor-obra-audiência, um movimento rico em que o espectador dá

\footnotetext{
${ }^{19}$ FLUSSER, V. Filosofia da caixa preta: ensaios para uma futura filosofia da fotografia. São Paulo: Annablume, 2011.

${ }^{20}$ GIANNETTI, C. Estética digital: sintopia da arte, a ciência e a tecnologia. Belo Horizonte: C/Arte, 2006 , p. 105.

${ }^{21}$ Galanter, P. What Is Generative Art? Complexity Theory as a Context for Art Theory. In: 6th International Conference, Exhibition and Performances on Generative Art and Design. 2003. Disponível em: $<$ https://bit.ly/3hEVYeY>.

Acesso em: 15/09/2021.

${ }^{22}$ FLUSSER, 2008. Op. cit.

${ }^{23}$ HUI, Y. Tecnodiversidade. São Paulo: Ubu Editora, 2020, p. 119.
} 
continuidade à obra no próprio ato de fruir. A coautoria, na presente investigação, se estabelece antes na dimensão poética, neste híbrido de carne e cálculo ${ }^{24}$. É justamente essa cessão que permite a geração de imagens que, em partes, é fruto da imaginação numerizada ou maquínica acima explorada.

\section{Euncionamento e diferenças: velha e nova onda}

Com o desenvolvimento observado na inteligência artificial durante as últimas décadas, "uma nova onda de arte algorítmica que usa a IA de novas maneiras para se fazer arte" ${ }^{25}$ se consolidou. A nova onda se contrapõe à arte algorítmica tradicional justamente porque, no contexto original, era o artista quem precisava codificar o programa sob um conjunto de regras determinadas que resultariam em obras com a estética desejada. Já no cenário baseado na aprendizagem de máquina, os algoritmos são ajustados pelo artista para reconhecerem padrões e aprenderem suas estéticas, podendo originar conjuntos de resultados ainda mais imprevistos do que nos casos de um código humanamente programado, justamente porque generativo.

Este ecossistema criativo e artístico remodelado, sob o qual se insere a nova onda, aproveita-se da circunstância de uma era tecnológica em que os algoritmos apresentam características autônomas e automáticas no exercício de suas funções, removendo uma barreira que limitava o uso destes recursos a artistas-programadores (aqueles iniciados ou com grande conhecimento em linguagens de programação), contrapondo-se ao método de criação experienciado por Harold Cohen com AARON, por exemplo. Cohen possuía domínio sobre o código pois era o responsável imediato pelas regras programadas no software.

O paradigma GOFAI ou inteligência artificial simbólica sob o qual Cohen desenvolveu AARON é um método que pressupõe que toda a dinâmica a ser executada pelo algoritmo precisa ser antecipadamente redigida, isto é, as ações a serem desempenhadas precisam ser convertidas em sintaxes maquinicamente inteligíveis (símbolos) para que o programa seja capaz de reproduzir os desejos manifestados pelo artista. O método GOFAI permite ao artista um controle superior sobre as obras, uma vez que o código é a pura manifestação lógica (ou a expressão codificada do pensamento do autor), muito embora o resultado nem sempre possa ser antecipado com precisão. O benefício representado pelo controle do sistema vem acompanhado do prejuízo sobre o ganho de escala, fator que fica comprometido uma vez que a geração de uma nova obra invariavelmente demanda ajustes manuais no código, que podem ser mais ou menos demorados dependendo do resultado esperado.

Cenário diferente é experimentado nas criações em que são convocadas interfaces inteligentes que operam sob redes neurais, uma vez que inúmeras variáveis para a produção artística já se encontram codificadas, e outras espécies de imaginações artificiais surgem da própria capacidade generativa dessas redes de se auto modificarem e de modificarem os próprios resultados criativos, especialmente em razão do treinamento a que são submetidas. Ao suprimir do artista uma parte importante do processo de formulação estética e formal de uma dada imagem, seja esta uma imagem mental ou a iconografia de uma realidade fenomênica, ganha-se em escala, mas perde-se em precisão e - ainda mais - em previsibilidade. Isso pode ser desejável.

Há uma vasta coleção de algoritmos que integram a nova onda de IA orientada à criação artística, o que resulta em uma sopa de letrinhas difícil de digerir. Em comum, porém, observa-se que a maioria destes algoritmos são baseados nas já mencionadas GANs, uma classe de códigos complexos baseados em deep learning que fornecem as bases para o treinamento de modelos generativos.

Tal modelagem se dá a partir de um método de aprendizagem não supervisionada, condição que capacita as interfaces com habilidades de identificar padrões em dados submetidos ao algoritmo (coleções diversas que podem variar de cálculos matemáticos a fotografias, passando por áudio, vídeo e pintura) e consequentemente produzir dados originais com alto grau

\footnotetext{
${ }^{24}$ COUCHOT, E. A natureza da arte: o que as ciências cognitivas revelam sobre o prazer estético. São Paulo: Editora Unesp, 2019.

${ }^{25}$ Elgammal; Mazzone, Op. cit., p. 2.
} 
de similitude de modo que os dados gerados poderiam ser considerados como excertos da coleção na qual foram treinadas ${ }^{26}$. Trazendo para o contexto deste artigo, as GANs podem ser utilizadas para gerar imagens originais, nunca vistas, baseadas em bancos de dados diversos, sejam eles compostos por fotografias, pinturas, imagens digitais etc.

Estes algoritmos se diferenciam em nível de complexidade de outros modelos matemáticos ("velha onda" ou GOFAI) porque operam em constante confronto e, com isso, assumem um potencial criativo autônomo importante. Em resumo, redes neurais rompem com a estratégia de Cohen/AARON, baseada na formulação de regras, em direção a um cenário em que as interfaces inteligentes são treinadas na esfera da apreensão e da compreensão estéticas, acentuando a criatividade artificial.

As GANS são compostas por duas redes neurais, uma geradora $(G)$ e uma discriminadora (D) que competem entre si para originar algo novo. Nelas, "o modelo generativo é confrontado com um adversário: um modelo discriminativo que aprende a determinar se uma amostra é da distribuição do modelo [imaginado pelo algoritmo, algo falso] ou da distribuição de dados [de coleções existentes, algo legítimo]”27. Redes neurais generativas atuam no domínio latente nos modelos a que são submetidas e essa característica representa um grande passo no desencadeamento de estímulos criativos, especialmente quando se consideram as hibridações entre interfaces inteligentes e artistas talentosos.

Todo esse entendimento orientado ao funcionamento das redes neurais, contudo, deixa de ser necessário no exercício da poética desempenhada com o auxílio de interfaces como a Playform: o profundo conhecimento em sistemas expertos para o uso de algoritmos torna-se tangencial uma vez que toda a interação homem-máquina na plataforma é intermediada por meio de uma GUI (graphical user interface) amigável, baseada em operações tão simples quanto rabiscar, clicar, arrastar e soltar. Sob suas redes neurais, no entanto, esconde-se o complexo emaranhado que simula, dentro das limitações informáticas atualmente disponíveis, as capacidades humanas enquanto processa informações - imagens - muito rapidamente. A retaguarda que suporta a criatividade artificial da Playforme de outras interfaces semelhantes se estabelece sob os auspícios das redes neurais generativas acima exploradas.

Diante das habilidades percebidas nas interfaces inteligentes atuais, a comparação (no sentido de colocar em perspectiva, e não de apontar qualidades e defeitos) com os processos experimentados pelos precursores da computer art parece inevitável; uma comparação que escancara a velocidade das mutações tecnológicas e a capacidade de os artistas assimilarem tais mutações. As colaborações exigidas dos artistas com engenheiros e especialistas em linguagens de programação e operação de computadores para permitir a usabilidade dos sistemas inteligentes e terminais passa por mudanças (ou pela completa substituição): o elemento humano se metamorfoseia em sistemas inteligentes.

As históricas três etapas "no processo de produção de computação gráfica”, descritas por Reichardt (apresentação das ideias pelo comunicador ou artista; interpretação das ideias pelo especialista; conversão das ideias em linguagem de máquina) ${ }^{28}$ encontram-se agora condensadas em uma operação rápida e natural. O processo não mais apresenta tantas dificuldades intransponíveis, convidando o artista a experimentar e reformulando os modos de criar com apenas um parceiro, agora formado por bytes e bits. A associação homem-máquina é estabelecida com a mesma facilidade com que um dispositivo é conectado à Internet.

26 BrownleE, J. A Gentle Introduction to Generative Adversarial Networks (GANs). Disponível em: $<$ https://bit.ly/3lvy0nP>. Acesso em: 24/04/2021.

${ }^{27}$ Goodfellow, I. et al. Generative Adversarial Nets. 2014. Disponível em: <https://arxiv.org/abs/1406.2661>. Acesso em: 01/05/2021.

${ }^{28}$ REICHARDT, Op. cit., p. 71, tradução nossa. 


\section{Criatividade numerizada e antropomorfização}

É nesta dinâmica criativa impulsionada por sistemas como Playform que parece se consumar uma espécie de transposição do ser biológico para o interior de um corpus artificial, que por sua vez encontra-se situado em uma dimensão que reformula a maneira tradicional de criação e reposiciona as interações homem-máquina: à práxis artística assistida são impostos elementos que desestabilizam algumas certezas diante da intangibilidade tecnológica e simbólica que a cerca.

A partir do momento em que o artista-operador cede intencionalmente à interface parte de seu poder de criação, uma dinâmica que compreende a coautoria é desencadeada, e essa cessão resulta invariavelmente na geração de imagens a partir de uma imaginação algorítmica que estabelece a poética sob os termos da digitalização. Neste remix numérico que se consolida a partir do treinamento em imagens de acervo e que se organiza, amiúde, de modo automático, visando novas experiências visuais e criativas, pode-se se questionar "o que constitui a relação de autoria que um artista tem com uma obra quando, em uma leitura, o artista parece ter criado pouco do seu conteúdo" ${ }^{29}$, conferindo às máquinas quase toda uma aparente vontade artística? A questão é instigante.

É sempre possível argumentar que sobre as imagens geradas numericamente o artista possui papel determinante: pode alterá-las, rejeitá-las, cortá-las; diante do conjunto de figuras o artista pode assumir a posição de curador ao selecionar e atribuir sentido crítico à criação; frequentemente, o artista também pode optar por alimentar algoritmos com obras de sua própria autoria, oferecendo à máquina a possibilidade de aprender uma estética ainda mais particular. O feedback homemmáquina permanece preservado e o papel do artista, assegurado. No entanto, a figura do artista enquanto gênio criador é colocada em suspensão - e isto parece irreversível.

A transferência de capacidades orgânicas às máquinas - "entre as quais podemos contar uma certa forma de imaginação” 30 , uma característica que a Baudelaire parecia inalienável - é o reconhecimento contumaz do deslocamento de habilidades entre corpos de diferentes naturezas, ocasionando um distúrbio na atribuição de criatividade e autoria. Parece que com a arte numérica "Não é mais somente a categoria dos criadores de imagens, mas a dos autores em geral que é destituída dos privilégios, os quais não eram atribuídos à máquina antigamente” ${ }^{31}$.

Segundo Max Bense, o ato de antropomorfizar "máquinas e mecanizar homens são tendências cruzadas que com certeza ocorrerão no futuro, mas a extensão à qual o homem e a máquina estarão unidos é incerta”32. A humanização de interfaces e a tecnização dos seres humanos, discutidas no âmbito da exposição Cybernetic Serendipity (1968), foram determinantes para pensar o estabelecimento de formas criativas engendradas pela tecnologia, e tal reflexão se articula na noção de criatividade em tensionamento com o digital e, ao mesmo tempo, em relação ao humano.

Embora os seres humanos sejam organicamente dotados de criatividade, pensamento e intuição, e na maioria dos eventos históricos tenham estado à frente dos processos de dominar uma variedade de disciplinas diferentes, tal conclusão torna-se cada vez mais um traço não essencial da criatividade e do pensamento naturalmente atribuído à raça humana, e parece estar cada vez mais evidente que o digital se aproxima de características biológicas. Tal constatação parece particularmente clara na esfera do criativo.

Nesta direção, assinala Roy Ascott, os meios eletrônicos baseados sobretudo em tecnologias de computação e telecomunicações são fenômenos que "estão exercendo enorme influência na sociedade e no comportamento individual; eles

\footnotetext{
${ }^{29}$ IRVIN, S. Appropriation and Authorship in Contemporary Art. In: British Journal of Aesthetics, Vol. 45, No. 2. 2005, p. 127.

${ }^{30}$ COUCHOT, E. A tecnologia na arte: da fotografia à realidade virtual. Porto Alegre: Editora da UFRGS, 2003 , p. 156.

${ }^{31}$ Ibidem, p. 156.

${ }^{32}$ BENSE, M. Cybernetic Serendipity. The Magazine of the Institute of Contemporary Arts, [S. 1.], v. 6, n. 2, 1968, p. 5, tradução nossa.
} 
parecem estar cada vez mais questionando a própria natureza do que é ser humano, ser criativo, pensar e perceber, e de fato nossa relação uns com os outros e com o planeta como um todo"33.

A tradução do potencial humano em diversas áreas rumo a uma linguagem de sistema simbólico compreensível por máquinas de cálculo, associadas à capacidade de processamento dessas mesmas máquinas, ao conhecimento humano que retroalimenta neurônios digitais por sua vez acoplados a algoritmos avançados capazes de reconhecer padrões e a aprender autonomamente seguramente irá dominar uma porção de segmentos da sociedade nas próximas décadas, e o cenário artístico não ficará alheio a essas revoluções: a emergência do artífice numerizado é real.

\section{O desafio: pensar biologicamente sobre sistemas numéricos}

Ao se tratar as interfaces tecnológicas inteligentes enquanto corpos inorgânicos, e diante do reconhecimento da inexistência de atores dominantes, mas sim da prevalência da cooperação entre sistemas biológicos e artificiais, é possível pensar em termos de características orgânicas aplicadas a sistemas simbólicos. Essa inferência pressupõe que os sistemas artificiais são capazes de racionalizar a comunicação entre os corpos de diferentes naturezas. Em certa medida, como visto, isso já é possível graças à conversão de subjetividades orgânicas em linguagem simbólica, e aparatos como sensores de movimento, de medição de temperatura, pressão sanguínea, e outros mais complexos, como dispositivos de eletroencefalografia contribuem para a ascensão de mais e mais possibilidades. Combinadas, essas interfaces são capazes de reconhecer estados do corpo e interpretar algoritmicamente características biológicas.

As operações criativas vislumbradas a partir de combinações de software e hardware revelam-se potencialmente interessantes uma vez que permitiriam, ao menos em teoria, incorporar nuances como sentimentos e sensações a sistemas estritamente artificiais. Aparentemente, estes são os elementos que definirão os passos à próxima evolução da arte desenvolvida a partir da dinâmica homem-máquina, e são estes os atributos que poderão dominar as colaborações mais interessantes ao longo das próximas décadas.

Atualmente, a maior parte da criação assistida numericamente incorpora apenas conceitos traduzíveis em linguagem simbólica, bem como permite o aprendizado a partir da assimilação de padrões em conjuntos de dados; converter sentimentos em estruturas lógico-matemáticas é uma outra história, e parece oportuno explorá-la ainda que brevemente. É nesta direção que o pensamento de Lucille Suchman se mostra particularmente esclarecedor, sugerindo que o olhar seja lançado para tais qualidades biológicas incorporadas às tecnologias, sobretudo no contexto da Inteligência Artificial e da robótica (o que exigiria a adoção de dispositivos específicos):

Que figuras do ser humano são materializadas nestas tecnologias? Quais são as circunstâncias pelas quais as máquinas podem ser reivindicadas, ou vivenciadas, como humanas? E o que essas reivindicações e encontros nos dizem sobre os imaginários culturais particulares que informam essas iniciativas de tecnociência, e como poderiam ser de outra forma? ${ }^{34}$

As circunstâncias as quais Suchman se refere podem ser evocadas a partir de três atributos pelos quais a inteligência artificial pode vir a ser experimentada como ainda mais próxima da inteligência humana: as noções de embodiment, emoção e sociabilidade. Em conjunto, tais características revelam um corpus de possibilidades que podem ser incorporados aos sistemas

\footnotetext{
${ }^{33}$ ASCOTT, R.; SHANKEN, E. Telematic embrace: visionary theories of art, technology, and consciousness. Berkeley: University of California Press, 2003, p. 232, tradução nossa.

${ }^{34}$ SUCHMAN, Op. cit. p. 229, tradução nossa.
} 
inteligentes e que seriam capazes de aprimorar o já sofisticado ambiente de criação híbrido, justamente por ampliar as capacidades perceptivas das interfaces.

A noção de embodiment refere-se "tipicamente ao nosso ser enquanto entidades vivas, sentimentais, corporais situadas em um mundo físico" ${ }^{35}$. No campo da computação e mais precisamente em IA, embodiment é aplicado aos agentes ou "entidades" que, acoplados a sensores, transmissores e motores permitem que máquinas dividam o espaço com seres biológicos e se engajem em tarefas colaborativas; isso simboliza a interação homem-máquina (Human-computer Interaction ou HCI). Embodiment é, portanto, uma capacidade inata aos seres humanos e que é transferida aos computadores (por intermédio de ferramentas, sensores, biossensores e IA) de modo a oferecer às interfaces tais habilidades. Isso se traduz ou é um sintoma da "materialização da humanidade" descrita por Suchman. Em seus próprios termos, "as descobertas do corpo em inteligência artificial e robótica inevitavelmente localizam sua importância em face das operações bem-sucedidas da mente ou pelo menos de alguma forma de cognição instrumental”36.

O fator emoção, não raramente descrito como elemento da computação afetiva ${ }^{37}$, é destacado por Suchman como "o ingrediente que falta para a participação plena (se não igual) da máquina no mundo humano" 38 . Embora considere que tal ingrediente talvez nunca chegue a ser incorporado às máquinas, Suchman reconhece que mesmo em pequena escala o fator emocional ofereceria um salto importante na capacidade maquínica, alavancando-as de meros sistemas expertos para "atores perceptivos em sociedade" ${ }^{39}$.

Nesta direção, projetos baseados em IA como The Painting Fool, de Simon Colton, mostram que as capacidades afetivas em máquinas podem estar cada vez mais próximas. No presente exemplo, a interface é programada para exibir atitudes consideradas como "habilidosas, elogiosas e imaginativas" e o projeto tem sido adotado para abordar noções como "emoção e intencionalidade” em inteligências não biológicas. Se é verdade que tanto os processos emocionais quanto a razão são elementos essenciais à inteligência, então a capacidade que as interfaces têm incorporado para perceber reações (através dos sensores mencionados em embodiment) e processar suas nuances - ocupando-se para isso de treinamentos em bons e diversificados datasets - deverão em breve avançar mais um estágio. Seria possível pressupor que tais aplicações poderiam ser implementadas, com significativo grau de dificuldade, em interfaces como Playform por intermédio de APIs ${ }^{40}$. Tal reflexão, contudo, se baseia em suposições. Seria necessário, para levar a cabo tal projeção, que a plataforma liberasse publicamente os protocolos que permitiriam a comunicação entre diferentes sistemas, o que seria desejável tanto do ponto de vista criativo (com a abertura de novas possibilidades poéticas, incorporando maneiras inéditas de expressão) quanto tecnológico. Essa ideia, contudo, não parece refletir os planos da plataforma e apenas salienta uma possibilidade informática.

Finalmente, a noção de sociabilidade emerge do que Suchman chama de "nova Inteligência Artificial", uma IA que se "afasta do processamento de informações simbólicas [e se volta] para a humanidade como embodiment, afeto e interatividade" $^{41}$. Compreende-se que neste estágio de humanização da tecnologia Suchman sugere uma união completa entre os três conceitos apresentados, pressupondo o uso massivo de sensores de percepção, técnicas avançadas de IA capazes de

${ }^{35}$ Marshall, P.; Hornecker, E. Theories of Embodiment in HCI. In: Price, S.; Jewitt, C.; Brown, B. (Org.). The Sage handbook of digital technology research. Londres: Sage Publications, 2013, p. 144, tradução nossa.

${ }^{36}$ SUCHMAN, Op. cit., p. 230, tradução nossa.

${ }^{37}$ PICARD, Op. cit.

${ }^{38}$ SUCHMAN, Op. cit., p. 232, tradução nossa.

${ }^{39}$ Ibidem, p. 230, tradução nossa.

${ }^{40}$ Application Programming Interface ou Interface de Programação de Aplicativos é uma espécie de protocolo que permite que um sistema (A) converse com outro (B), permitindo que (A) adquira novas funções para as quais não foi originalmente programado.

${ }^{41}$ SUCHMAN, Op. cit., p. 235, tradução nossa. 
deslocar as interfaces de uma zona de conforto (o processamento simbólico) para o que pode ser compreendido como processamento de linguagem natural, entendendo por "linguagem" um complexo arcabouço que compreende a fala (sobretudo), os gestos e as expressões.

Ao serem capazes de analisar as interações de um ser humano, e nessas interações identificar estados emocionais de fundo, tais sistemas complexos podem adquirir capacidade de exprimir sinais associados às emoções, condição que torna as interfaces ainda mais "naturais", interessantes e convidativas ao exercício da práxis artística. Ao assumir em definitivo a condição de sistemas empáticos, que podem ser afetivos e receptivos aos sentimentos identificáveis no outro por intermédio de avaliações de estados do corpo, estes sistemas complexos tendem a adquirir uma fascinante e ainda mais complexa autonomia.

\section{considerações finais}

A inteligência maquínica experienciada até agora emergiu, em determinado momento, da engenhosidade humana e de suas capacidades biológicas de sistematizar, rotular e aplicar conjuntos de dados à solução de problemas. Mas à medida que tais capacidades são transferidas para interfaces inorgânicas inteligentes, e cientes de que estas interfaces estão cada vez mais adaptadas e aptas ao reconhecimento de estímulos e emoções, dotadas de neurônios artificiais e de inigualáveis capacidades de processamento computacional, é possível sugerir que máquinas estão profundamente envolvidas no ato criativo. $\mathrm{O}$ exemplo adotado neste artigo, Playform, é apenas uma entre as diversas formas de se automatizar a criação e ceder a uma entidade inorgânica a tarefa de imaginar fenômenos zerodimensionais que podem se manifestar sob a forma de imagens técnicas (mas também de literatura, poesia ou até mesmo em outros códigos matemáticos).

A questão da autoria (problema importante, mas apenas um entre os diversos dilemas que emergem da simbiose homemmáquina na esfera da criação), não deveria ser observada sob uma perspectiva unificada, senão compartilhada. Dos anos 1960 até agora, a tecnologia passou por imensas transformações que foram capazes de abrir novas frentes de atuação para artistas. Harold Cohen deu o pontapé inicial e escreveu seu nome na história da arte ao colaborar com um sistema inteligente AARON - que ele próprio programou. No século XXI, inovações algorítmicas capitaneadas por redes adversárias generativas, cujo trabalho seminal de Goodfellow et al. em 2014 surgiu como espécie de manifesto para desencadear uma nova onda de IA, introduziram na aprendizagem profunda novos agentes artificiais capazes de competirem entre si para gerar conteúdos visuais inéditos.

Interfaces inteligentes como a Playform surgiram, na sequência, como interagentes para facilitar o uso e aplicação destes conceitos (códigos, ou textos científicos), ampliando sua adoção a um público de criativos que não necessariamente possuem expertise em programação. As noções de embodiment, emoção e sociabilidade vistas em Suchman, publicadas ainda no primeiro decênio deste século, destrincham um panorama (que neste artigo foi brevemente apresentado) que permite associar inteligência artificial a sensores capazes de mensurar estados do corpo, converter estes estados em dados e abastecer algoritmos com informações cada vez mais orgânicas e naturais. O resultado disso para a arte ainda é incerto de cravar, mas as possibilidades ventiladas sugerem que sistemas inteligentes podem se tornar cada vez mais ativos e precisos no processo de criação, justamente por serem capazes de interpretar estados e sensações, não mais apenas a linguagem.

Este trabalho buscou articular noções caras ao entendimento da arte em tensionamento com a inteligência artificial a partir de conceitos clássicos e contemporâneos, tendo como horizonte o cenário em que se observa a criação assistida por sistemas expertos cada vez mais aptos a incorporarem qualidades e elementos inerentes aos seres humanos. Mas a complexidade atualmente experimentada está muito distante de tudo o que pode ser feito no campo da IA. A simulação das atividades neuronais, por exemplo, encontra-se ainda em estágio incipiente, e emular a inteligência humana permanece um dos desafios mais significativos destes tempos. 
Indícios sugerem que antes de se emular o cérebro humano será necessário passar pelo sistema nervoso dos invertebrados, dos pequenos mamíferos e dos grandes mamíferos, para só então ousar uma digitalização do cérebro humano ${ }^{42}$. $\mathrm{O}$ longo caminho a ser percorrido será acompanhado de perto pelas interfaces inteligentes, uma vez que as redes neurais, salvo determinados ajustes, são as mesmas independente da aplicação pretendida (ou seja, os avanços feitos em um laboratório de neurociência podem ser absorvidos por especialistas de outras áreas). Quais implicações esses avanços trarão para o campo da arte?

As provocações aqui expostas passearam apenas pela superfície do arcabouço de problemáticas passíveis de desdobramentos em questões fundamentais para o entendimento do cenário que pode vir a se desenhar para a arte ao longo dos próximos anos, uma conjuntura em que a discussão da criatividade deverá, cada vez com mais afinco, ser estendida e debatida na dimensão do artificial, sugerindo novos desafios.

Argumentos contrários à criatividade maquínica são numerosos e não há indícios que sugiram seu desaparecimento. Sempre haverá momentos de confronto em que um sujeito poderá dizer que as máquinas somente estão fazendo o que foram programadas para fazer; isso é verdadeiro. Ao mesmo tempo - e de certo modo, seres humanos também fazem somente aquilo que foram programados para fazer, e isso não entra em conflito com (ou não representa um impeditivo para) o desempenho de atividades criativas: "não está claro que ser 'programado' (neste sentido) é incompatível com ser criativo ou livre" ${ }^{43}$.

Finalmente, percebe-se que ao não ser nem mero procedimento formal, tampouco simples exercício de inteligência, a arte envolve questões suplementares e que evocam sentimentos, sensações, estados de humor e tantas condições e características que ainda não foram plenamente adaptadas à linguagem de máquina. Será preciso acompanhar a escalada numérica para verificar em que medida isso afetará a arte criada ou assistida por sistemas inteligentes. As habilidades destas interfaces são inegáveis e incluem velocidade, escalabilidade, capacidade de aprendizagem e reconhecimento de padrões. São também dotadas de todos os recursos necessários para exprimir graficamente as mais variadas abstrações simbólicas e numerizadas. Mas isso é tudo?

\section{Referências bibliográficas}

Ascott, R.; Shanken, E. Telematic Embrace: Visionary Theories Of Art, Technology, And Consciousness. Berkeley: University Of California Press, 2003.

BENSE, M. Cybernetic Serendipity. The Magazine Of The Institute Of Contemporary Arts, [S. L.], V. 6, N. 2, 1968.

Bostrom, N. Superinteligência: Caminhos, Perigos, Estratégias. Rio De Janeiro: Darkside, 2018

BRownleE, J. A Gentle Introduction To Generative Adversarial Networks (GANS). Disponível em: <https://Bit.Ly/3lvy0np>. Acesso em: 24/04/2021.

Couchот, E. A Tecnologia Na Arte: Da Fotografia À Realidade Virtual. Porto Alegre: Editora Da Ufrgs, 2003.

Cоuснот, E. A Natureza Da Arte: O Que As Ciências Cognitivas Revelam Sobre O Prazer Estético. São Paulo: Editora Unesp, 2019.

Elgammal, A.; Mazzone, M. Artists, Artificial Intelligence And Machine-Based Creativity In Playform. Artnodes, [S. L.], N. 26, 2020. Disponível em: <https://Doi.Org/10.7238/A.V0i26.3366>. Acesso em: 11/05/2021.

FluSSER, V. O Universo Das Imagens Técnicas: Elogio Da Superficialidade. 1. Ed. São Paulo: Annablume, 2008.

${ }^{42}$ Bostrom, N. Superinteligência: Caminhos, perigos, estratégias. Rio de Janeiro: DarkSide, 2018, n.p.

${ }^{43}$ Haugeland, Op. cit., p. 10, tradução nossa. 
Flusser, V. Filosofia Da Caixa Preta: Ensaios Para Uma Futura Filosofia Da Fotografia. São Paulo: Annablume, 2011.

Galanter, P. What Is Generative Art? Complexity Theory As A Context For Art Theory. In: 6th International Conference, Exhibition And Performances On Generative Art And Design. 2003. Disponível em: <https://Bit.Ly/3hevyey>. Acesso em: 15/09/2021.

Giannetti, C. Estética Digital: Sintopia Da Arte, A Ciência E A Tecnologia. Belo Horizonte: C/Arte, 2006.

Goodfellow, I. Et Al. Generative Adversarial Nets. 2014. Disponível em: <https://Arxiv.Org/Abs/1406.2661>. Acesso em: 01/05/2021.

Haugeland, J. Artificial Intelligence: The Very Idea. Massachusetts: Mit Press, 1985.

IRVIN, S. Appropriation And Authorship In Contemporary Art. In: British Journal Of Aesthetics, Vol. 45, No. 2. 2005 , P. 127.

Marshall, P.; Hornecker, E. Theories Of Embodiment In Hci. In: Price, S.; Jewitt, C.; Brown, B. (Org.). The Sage Handbook Of Digital Technology Research. Londres: Sage Publications, 2013.

PICARD, R. Affective Computing: Challenges. International Journal Of Human-Computer Studies. Londres, V. 59, P. 5564, 2003. Disponível em: <https://Doi.Org/10.1016/S1071-5819(03)00052-1>. Acesso em: 08/09/2021.

REICHARDT, J. Computer Art. In: Cybernetic Serendipity: The Computer And The Arts. Londres: Studio International, 1968, P. 71.

SUCHMAN, L. Human-Machine Reconfigurations Plans And Situated Actions. Cambridge: Cambridge Univ. Press, 2007.

WooD, P. Arte Conceitual. São Paulo: Cosac \& Naify, 2004

ZuAnon, R. Computador Vestível Afetivo Co-Evolutivo: Processos De Comunicação Entre Corpos Biológico e Tecnológico. Tese. Programa De Doutorado Em Comunicação E Semiótica, Pontifícia Universidade Católica De São Paulo, 2007.

ZuANON, R. Biointerfaces Inteligentes: Transdisciplinaridade E Transversalidade Em Arte-Arquitetura-Design-CiênciaTecnologia. In: Celeste, H. Et Al. (Org.). Transdisciplinaridade Nas Ciências E Nas Artes. Santa Maria: Editora Ppgart, 2020.

HUI, Y. Tecnodiversidade. São Paulo: Ubu Editora, 2020. 